\title{
Fish-seaweed association on temperate reefs: do small-scale experiments predict large-scale patterns?
}

\author{
Phillip S. Levin ${ }^{1, *}$, Mark E. Hay ${ }^{2}$ \\ ${ }^{1}$ Northwest Fisheries Science Center, National Marine Fisheries Service, 2725 Montlake Boulevard E, Seattle, \\ Washington 98118, USA \\ ${ }^{2}$ School of Biology, Georgia Institute of Technology, Atlanta, Georgia 30332-0230, USA
}

\begin{abstract}
Processes affecting reef fish populations are likely to vary with spatial scale, but there have been few attempts to determine whether predictions generated by small-scale experiments are manifested at larger spatial scales. Our goal in this study was to determine if patterns of microhabitat use measured in small-scale experimental manipulations scaled-up and allowed predictions of among-reef patterns of abundance across larger spatial scales. Manipulations of algal biomass in artificially created $1.5 \mathrm{~m}^{2}$ plots indicated that patches of Sargassum filipendula supported greater numbers of slippery dick Halichoeres bivittatus than those with an equal biomass of Zonaria tournefortii, or than patches with an equal mix of $S$. filipendula and $Z$. tournefortii. Scaling up and manipulating $S$. filipendula and $Z$. tournefortii abundance in $100 \mathrm{~m}^{2}$ sections of reef produced results qualitatively similar to the small-scale experiments; fish densities varied as a function of $S$. filipendula mass. Larger scale surveys of fish densities and algal biomass on large reefs separated by 1 to $30 \mathrm{~km}$ showed positive associations between fish density and $S$. filipendula biomass. For the reefs that we studied, our small-scale experiments scaled up and predicted large-scale patterns of abundance on reefs in the South Atlantic Bight.
\end{abstract}

KEY WORDS: Reef fish $\cdot$ Temperate reef $\cdot$ Habitat structure $\cdot$ Macroalgae $\cdot$ Scale $\cdot$ Recruitment

\section{INTRODUCTION}

Marine organisms with pelagic larvae exist as a series of local populations connected by dispersal (Caley et al. 1996). For species that have limited movement as adults, this life history results in populations that are affected by processes occurring at 2 very different spatial scales (Sale 1998). At large scales (kilometers), populations of marine species may be affected by factors or processes that influence the survivorship of larvae in the plankton or the delivery of larvae to local populations (Doherty \& Williams 1988). After larvae settle to the benthos, processes such as predation and competition that act on scales of meters can influ-

*E-mail: phil.levin@noaa.gov ence the size and dynamics of populations. Populations may thus be affected by processes acting at both large and small spatial scales, and understanding the degree to which processes that act at small scales generate patterns that are detectable at large scales is a question of fundamental importance in ecology (e.g. Levin 1992, Sale 1998).

Most reef fishes stay closely associated with the reef on which they settle, and have limited post-settlement movement (Sale 1991). As a result, patterns of habitat use at scales of meters (microhabitat use) may affect the distribution of fishes at larger scales. The association of reef fishes with particular microhabitat attributes is common on both tropical and temperate reefs (Booth \& Wellington 1998). Moreover, large-scale patterns of fish abundance often correlate with habitat characteristics of reefs (e.g. Levin et al. 1997). While the literature is 
replete with studies of fish-habitat associations, most of these studies are conducted at a single spatial scale. Thus the degree to which among-reef patterns of abundance are predicted by among-reef variability in the amount of appropriate microhabitat is largely unknown (but see Tolimieri 1995, 1998a,b, Caselle \& Warner 1996).

On temperate rocky reefs much of the structure used by fishes is provided by macroalgae, which are dynamic and vary both spatially and temporally as a result of biotic and abiotic disturbances (e.g. Chapman \& Johnson 1990, Steinberg et al. 1995, Renaud et al. 1997). The structural complexity of algal habitats serves as an important refuge from predation (Ebeling \& Laur 1985, Schmitt \& Holbrook 1985, Tupper \& Boutilier 1997), and invertebrates associated with algal beds provide rich food resources (Holbrook \& Schmitt 1988, Levin 1994). Variability in both canopy-forming and understory seaweeds affects initial patterns of fish recruitment (Jones 1984, Carr 1991, Levin 1991, 1993) as well as subsequent patterns of adult abundance (e.g. Choat \& Ayling 1987, Holbrook et al. 1990). Additionally, responses of fishes to macroalgal patches may vary tremendously as a function of the algal species comprising a patch (Levin \& Hay 1996). Thus, understanding how fishes respond to variable seaweed abundance and species composition, as well as how this response changes with scale, may be critical for understanding the dynamics of reef fish populations.

Previous work attempting to predict large-scale patterns of fish abundance from microhabitat preferences has been (1) largely based on descriptive patterns of microhabitat use, and (2) conducted primarily on tropical reefs. In this study, we experimentally determined microhabitat use by the common wrasse Halichoeres bivittatus (slippery dick) on deep temperate reefs on the continental shelf of North Carolina, USA. We then determined if the patterns of microhabitat use that we observed in small-scale experiments were lost in the complexities associated with larger spatial scales (e.g. Tolimieri 1995, Caselle \& Warner 1996). To this end, we examined how recruitment of slippery dicks was affected by variability in seaweed abundance and species composition at 3 different spatial scales: (1) artificially created seaweed patches of $1.5 \mathrm{~m}^{2}$ separated by about $5 \mathrm{~m}$, (2) numerous $100 \mathrm{~m}^{2}$ sections of natural reefs where we manipulated the natural cover of seaweeds, and (3) entire unmanipulated reef sites separated from each other by 1 to $30 \mathrm{~km}$.

\section{MATERIALS AND METHODS}

Study site and organisms. This study was conducted on 27 to $33 \mathrm{~m}$ deep rocky reefs located off the coast of
Wilmington, North Carolina, USA (near $34^{\circ} 10^{\prime} 09^{\prime \prime} \mathrm{N}$, $\left.77^{\circ} 23^{\prime} 12^{\prime \prime} \mathrm{W}\right)$. These reefs consist of an upper flat hardbottom, a scarp and rubble ramp complex, and a lower sand flat (Riggs et al. 1985, Renaud et al. 1996, 1997). The upper hardbottom is an extensive flat limestone surface covered with a thin layer of sand. Near the edge of the upper hardbottom, the substrate is generally free of sand and covered by a dense bed of brown algae dominated by Sargassum filipendula, Dictyopteris hoytii, and Zonaria tournefortii. Dictyota spp., Lobophora variegata and Dictyopteris membranacea are also present, but are consistently less abundant (Levin \& Hay 1996). On its shallower side, the algadominated portion of the reef merges into a sandscoured flat that is very sparsely populated by seaweeds and sessile invertebrates. The upper hardbottom grades into the scarp and rubble ramp complex, which is a narrow, steep feature (1 to $5 \mathrm{~m}$ on our reefs) inhabited by a diverse assemblage of invertebrates and algae. A lower sand flat, devoid of seaweeds and sessile invertebrates, occurs at the bottom of the scarp and rubble ramp.

Habitats along the edge of the upper hardbottom and on the scarp and rubble ramp support a diverse assemblage of tropical and temperate fishes, with greater than 114 species representing 43 families (Grimes et al. 1982, Sedberry \& van Dolah 1984). Small wrasses (primarily slippery dick Halichoeres bivittatus) are especially common and, like many other species on these reefs, use seaweed beds along the edge of the upper hardbottom as recruitment habitat (Levin \& Hay 1996).

Slippery dicks occur from Bermuda and the Carolinas south to Brazil in coral reef, rubble, and seagrass habitats as well as on rock jetties and vegetated temperate reefs like those studied here (Randall 1968, Bohlke \& Chaplin 1993). Their diet consists largely of invertebrates, particularly crabs, sea urchins, and polychaetes (Randall 1968). After a larval life that averages 24 d (Victor 1986), slippery dicks settle to the benthos, where they spend ca. $5 \mathrm{~d}$ buried in sediment (Victor 1983). Settlement occurred exclusively during the summer months in our study sites. As new recruits, slippery dicks are site-attached and do not stray far from cover (Victor 1982). However, as adults (140 to $180 \mathrm{~mm}$ total length, TL) they are quite mobile, but generally stay within a home range of ca. $7000 \mathrm{~m}^{2}$ (Thresher 1979). During our study, slippery dicks comprised about $55 \%$ of the site-attached fishes in our study site (no other single species exceeded $7 \%$ ); thus, we limited our focus to this species.

Do algal species differ in their influence on fish recruitment? Sargassum filipendula and Zonaria tournefortii were the dominant seaweeds at our sites (see 'Results'). Previous work demonstrated that densities 
of reef fishes were about 5 times greater in $S$. filipendula than in $Z$. tournefortii, with algal densities held constant in $1.5 \mathrm{~m}^{2}$ experimental plots (Levin \& Hay 1996). Because $S$. filipendula is, on average, 3 times taller and 4 times heavier than $Z$. tournefortii (Levin \& Hay 1996), the difference in fish densities between algal habitats could be the result of biomass differences between the seaweeds. Experiments in which algal height was manipulated while density was held constant suggested that some of the differences in fish densities between these algae resulted from quantitative biomass differences (Levin \& Hay 1996).

To explore further why small-scale fish densities are greater in Sargassum filipendula than in Zonaria tournefortii patches, we performed an experiment in which we created thirty-two $1.5 \mathrm{~m}^{2}$ patches of algae that varied in species composition or in mass. Each algal patch was constructed by attaching plants to four $1 \mathrm{~m}$ long ropes fastened with nylon tie wraps to two $1.5 \mathrm{~m}$ pieces of $0.90 \mathrm{~cm}$ diameter metal rod (rebar) that were separated by $1 \mathrm{~m}$ and parallel to each other. Seaweeds used to make these patches were removed from the reef, brought to a boat, weighed, returned to the bottom, and attached to rebar frames positioned adjacent to the reef on otherwise barren substratum. Eight replicate plots of $1000 \mathrm{~g}$ of $S$. filipendula, 8 plots of $1000 \mathrm{~g}$ of $Z$. tournefortii, 8 plots of $500 \mathrm{~g}$ of $S$. filipendula plus $500 \mathrm{~g}$ of Zonaria, and 8 plots of $500 \mathrm{~g}$ of only S. filipendula were arranged in a randomized block design in July 1994. Each of the 4 treatments within a block was separated from others by $>5 \mathrm{~m}$, and blocks were separated from each other by at least $7 \mathrm{~m}$. All blocks were placed on bare sand and separated from natural vegetated habitat by $>5 \mathrm{~m}$.

Three weeks after the algal patches were established, densities of slippery dick recruits (the only species recruiting to the plots in significant numbers) were estimated by visually censusing each replicate. Here we define recruits as young-of-the-year fish $<40 \mathrm{~mm}$ TL. Censuses followed procedures developed by Sale \& Douglas (1981) and used previously on similar algal plots (Levin 1993, Levin \& Hay 1996). A diver slowly approached a patch, and at a distance of $2 \mathrm{~m}$ recorded any slippery dicks hovering within $1 \mathrm{~m}$ of the patch. The diver then moved closer to the patch and counted fish before closely searching the algae by moving each plant to detect hidden recruits. A blocked analysis of variance with algal treatment as the main effect was used to test for differences in the mean number of slippery dick recruits occupying our different treatments. We assumed that the block by treatment interaction was zero (Wilkinson et al. 1996). An $F_{\max }$ test (Winer et al. 1991) indicated that variances were homogeneous.

Do the results of small-scale experiments scale up? To determine if the small-scale $\left(1.5 \mathrm{~m}^{2}\right)$ association of young-of-the-year fish with seaweeds predicts patterns at larger spatial scales, we manipulated algal

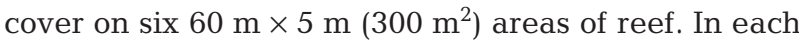
of the 6 areas, we removed Sargassum filipendula from a $20 \mathrm{~m} \times 5 \mathrm{~m}$ area $\left(100 \mathrm{~m}^{2}\right)$, removed Zonaria tournefortii from a $20 \mathrm{~m} \times 5 \mathrm{~m}$ area, and left these areas separated from each other by a $20 \mathrm{~m} \times 5 \mathrm{~m}$ area in which we did not manipulate algal cover (control). We also examined among-reef patterns of fish and algal abundance across 8 large reefs separated from each other by 1 to $30 \mathrm{~km}$.

In May 1995, we established 6 replicates of the 3 experimental plots on upper hardbottom areas of 6 reefs separated by $>1 \mathrm{~km}$. Each of the 3 plots on each reef extended $20 \mathrm{~m}$ along the reef edge and continued $5 \mathrm{~m}$ away from the reef edge. Plots were separated from each other by $10 \mathrm{~m}$. On each of the 6 reefs, divers removed, by hand, Sargassum filipendula from 1 plot, Zonaria tournefortii from a second plot, and left the third plot as a control. After 1 and $2 \mathrm{mo}$, fishes were censused along two $5 \mathrm{~m} \times 1 \mathrm{~m}$ transects in each of the 3 treatment plots on each of the 6 reefs. Transects were extended perpendicular to the reef edge and were $>5 \mathrm{~m}$ from each other and from the edge of the plot. Three minutes after a transect line was extended, a diver swimming at a rate of $\sim 3 \mathrm{~m} \mathrm{~min}^{-1}$ carrying a $\mathrm{T}$ shaped bar to delineate the transect width, carefully counted all fish along the length of the transect. Data from the 2 transects within each plot were summed. An analysis of variance was used to test for differences in the number of fish among algal removal treatments, with sampling date $(1$ and 2 mo after establishing treatments) and algal removal treatment considered as main effects. Sampling date was considered a random effect, while the algal removal treatment was considered fixed. After sampling fish, we quantified the percent cover (as a surrogate for algal biomass) of common algae to determine whether our algal removals had remained effective over the period since removal. Algal cover was estimated by sampling algae under 100 randomly selected points within each experimental plot.

To examine larger-scale patterns among reefs in the region, density of slippery dick recruits on 8 separate reefs was visually censused by determining fish abundance on six $30 \mathrm{~m} \times 1 \mathrm{~m}$ transects per reef in May 1994 . Reefs were selected by the captain of the RV 'Elusive' (National Undersea Research Center, Wilmington, NC) based on his local knowledge of reef locations and on his ability to detect them on the ship's depth recorder. We assumed that this method of choosing reefs would be unbiased, as we did not participate in the selection process and the captain was not informed of our hypothesis. Reefs used in the study were separated from each other by 1 to $30 \mathrm{~km}$. On each reef, 1 diver 
extended the transect line from a haphazard starting point on the upper hardbottom such that it was parallel and about $1 \mathrm{~m}$ away from the reef edge. Three minutes after the transect line was extended, a diver swimming at a rate of $\sim 3 \mathrm{~m} \mathrm{~min}^{-1}$ and carrying a T-shaped bar to delineate the transect width, carefully counted all fish along the length of the transect. After fish were censused, algae were removed from 20 haphazardly placed quadrats $\left(0.25 \mathrm{~m}^{2}\right)$ on each reef and placed in mesh bags. In the laboratory, seaweeds were separated by species, damp-dried and weighed. Regression analyses were used to examine among-reef associations between fish densities and Sargassum filipendula biomass.

\section{RESULTS}

\section{Do algal species differ in their influence on fish recruitment?}

When we created algal patches on barren sand where seaweeds did not normally occur, slippery dicks were significantly more abundant on patches composed of 1 $\mathrm{kg}$ of Sargassum filipendula than on patches made from $0.5 \mathrm{~kg}$ S. filipendula, $1 \mathrm{~kg}$ of Zonaria tournefortii, or $0.5 \mathrm{~kg}$ of $S$. filipendula plus $0.5 \mathrm{~kg}$ of $Z$. tournefortii $\left(F_{3,20}=4.56, \mathrm{p}=0.01\right.$, Tukey's HSD $<0.05$, Fig. 1 ; note that a single replicate of the $1 \mathrm{~kg} S$. filipendula treat-

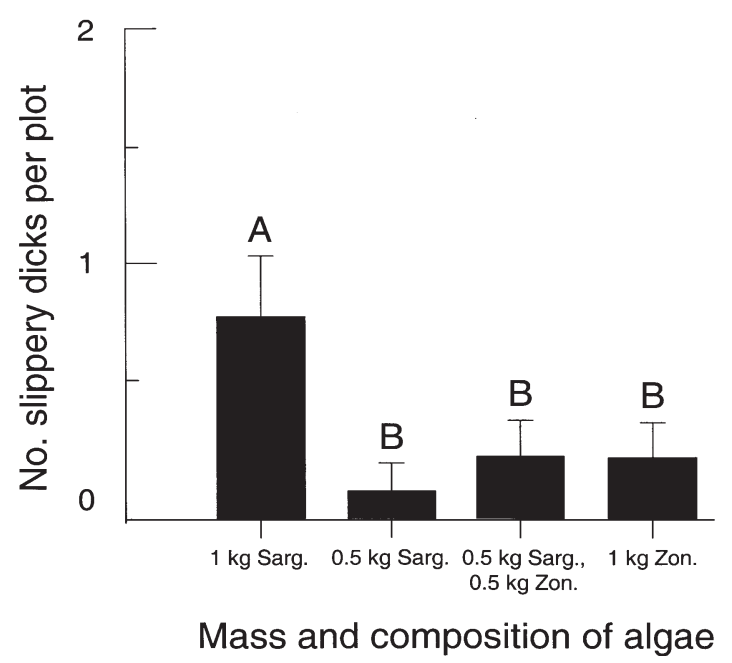

Fig. 1. Halichoeres bivittatus. Mean density of slippery dicks on experimental $1.5 \mathrm{~m}^{2}$ plots of varying Sargassum filipendula (Sarg.) or Zonaria tournefortii (Zon.) biomass ( $\mathrm{N}=8$ for each treatment). When placing algae in the ropes that held these treatments, algal mass was divided about equally among ropes so that algal mass and cover were spread equivalently throughout the $1.5 \mathrm{~m}^{2}$ area of each replicate. $p$ values are from an analysis of variance, and letters indicate means that were not significantly different in Tukey's HSD tests. Error bars are $\pm 1 \mathrm{SE}$ ment was destroyed and not included in analyses). There were no differences in fish density among the other 3 treatments. Thus, simply increasing algal biomass had no effect; only an increase in $S$. filipendula biomass yielded a response in density of slippery dicks. We also observed differences in fish density among blocks $\left(F_{7,20}=3.85, \mathrm{p}=0.01\right)$.

\section{Do the results of small-scale experiments scale up?}

\section{Large-scale experiment}

Our manipulations of $100 \mathrm{~m}^{2}$ areas were effective in producing treatments with different Sargassum filipendula and Zonaria tournefortii abundances for the 2 mo period of our experiment (Table 1). Two months after initial removal, the percent cover of Sargassum averaged about $84 \%$ less in S. filipendula removal plots than in control or $Z$. tournefortii removal plots. Likewise, the percent cover of Zonaria averaged about $78 \%$ less in $Z$. tournefortii removal plots than in control or S. filipendula removal plots. In $100 \mathrm{~m}^{2}$ plots from which $S$. filipendula had been removed, density of slippery dicks was significantly lower than in plots from

Table 1. Sargassum filipendula (Sarg.) and Zonaria tornefortii (Zon.). Mean (SE) percent cover in experimentally manipulated $100 \mathrm{~m}^{2}$ plots ( $\mathrm{N}=6$ for each treatment). Data were collected 2 mo after algae were first manipulated, at the end of the experiment. Letters to the right of each mean indicate means that were significantly different $(p<0.05)$ from each other (post hoc Tukey's HSD test)

\begin{tabular}{|lrr|}
\hline Treatment & Sarg. \% cover & Zon. \% cover \\
\hline Sarg. removal & $6.13(2.16) \mathrm{a}$ & $28.63(6.13) \mathrm{a}$ \\
Zon. removal & $39.01(7.92) \mathrm{b}$ & $4.90(3.42) \mathrm{b}$ \\
Control & $38.25(6.99) \mathrm{b}$ & $22.13(3.34) \mathrm{a}$ \\
\hline
\end{tabular}

Table 2. Halichoeres bivittatus. Analysis of variance on the densities of newly recruited slippery dicks on reefs in which Sargassum filipendula, Zonaria tournefortii, or no algae were manipulated ('algal removal' treatment). Reefs were considered blocks in the ANOVA. Data were $\log (x+1)$ transformed prior to analysis, and variances were homogeneous

\begin{tabular}{|lccccc|}
\hline Source & SS & df & MS & $F$ & $\mathrm{p}$ \\
\hline $\begin{array}{l}\text { Sampling date } \\
\begin{array}{l}\text { Algal removal } \\
\text { treatment }\end{array}\end{array}$ & 2.69 & 1 & 4.69 & 0.02 & 0.88 \\
$\begin{array}{l}\text { Sampling date } \\
\quad \times \text { algal removal } \\
\text { Error }\end{array}$ & 22.22 & 2 & 11.11 & 0.049 & 0.95 \\
\hline
\end{tabular}




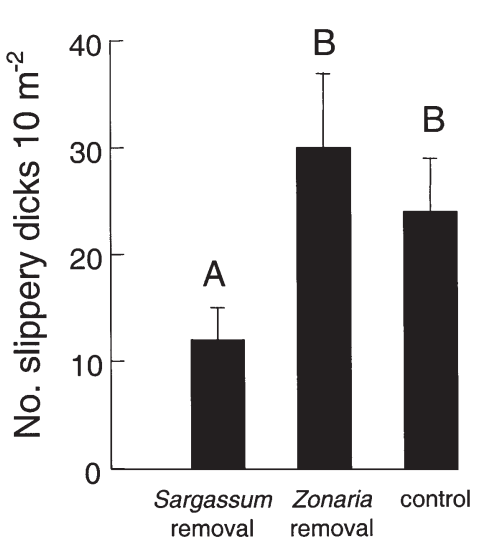

Fig. 2. Halichoeres bivittatus. Mean density of slippery dicks on experimental $100 \mathrm{~m}^{2}$ plots in which either Sargassum filipendula, Zonaria tournefortii, or no algae (control) were manipulated $(\mathrm{N}=6)$. Detailed results from the analysis of variance in Table 2. Letters indicate means that were not significantly different in Tukey's HSD tests. Error bars are $\pm 1 \mathrm{SE}$

which $Z$. tournefortii had been removed or in control plots (Table 2, Fig. 2). The density of slippery dicks in $S$. filipendula removal plots was about one-third of that in $Z$. tournefortii removal plots and half of that in control plots. Thus, as we observed in our small-scale experiment, when we reduced the biomass of $S$. filipendula, density of slippery dicks also was reduced. We were unable to detect a difference in slippery dick densities at periods of 1 mo versus 2 mo after algal manipulation (Table 2), suggesting that the spatial pattern we observed was consistent over time.

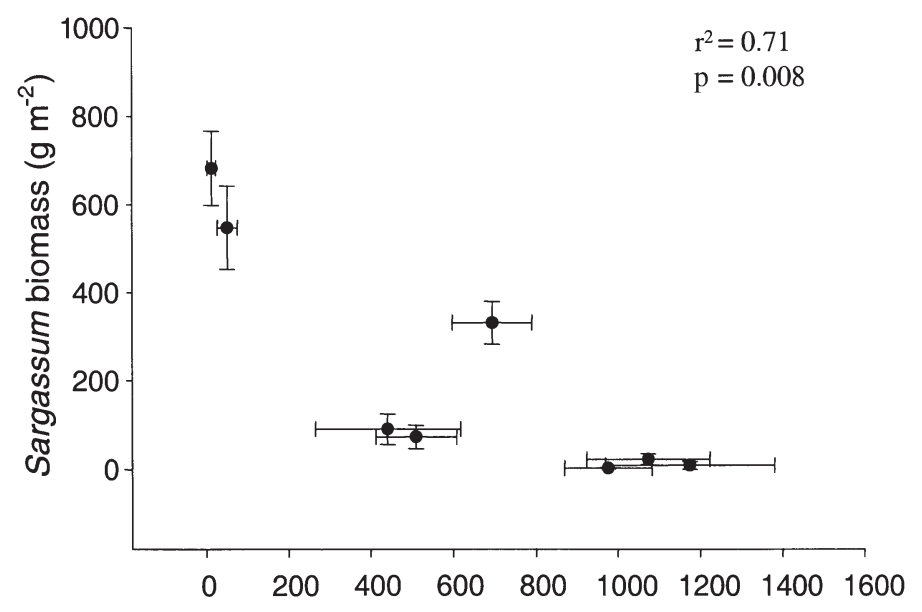

Zonaria biomass $\left(\mathrm{g} \mathrm{m}^{-2}\right)$

Fig. 3. Sargassum filipendula and Zonaria tournefortii. Relationship between the average biomass on reefs. $\mathrm{N}=8$ reefs.

Error bars are $\pm 1 \mathrm{SE}$

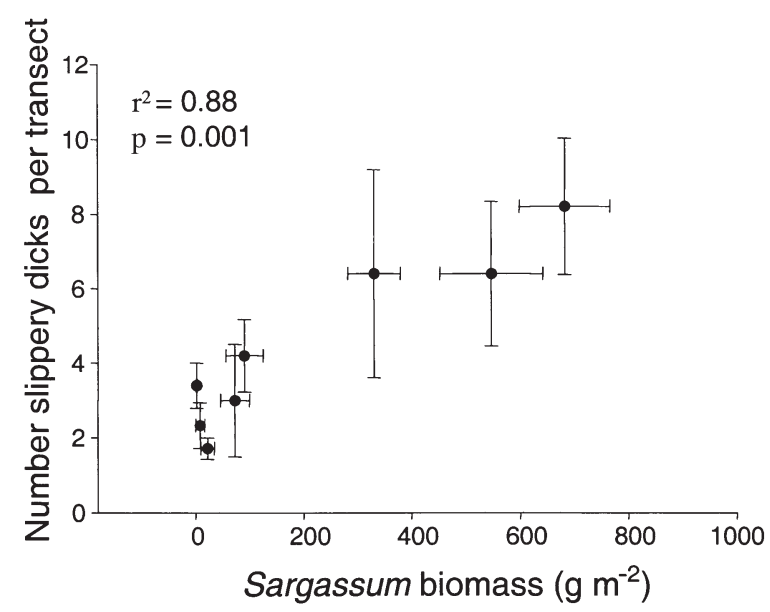

Fig. 4. Relationship between average biomass of Sargassum filipendula on a reef versus the average number of slippery dicks on a reef. $\mathrm{N}=8$ reefs. Error bars are $\pm 1 \mathrm{SE}$

Patterns among reefs

At the scale of entire reefs, there was a strong and significant inverse relationship between the biomass of Zonaria tournefortii and Sargassum filipendula $\left(r^{2}=0.71 ; p=0.008\right)$. Reefs with high $Z$. tournefortii biomass (ca. $>900 \mathrm{~g} \mathrm{~m}^{-2}$ ) had virtually no $S$. filipendula. Similarly, on reefs with high $S$. filipendula biomass, Z. tournefortii was rare or absent. As predicted by our previous experiments, there was a significant positive relationship between the average density of slippery dicks and the biomass of S. filipendula (Fig. 3). Eighty-eight percent of among-reef variance in mean slippery dick abundance was predicted by variation in S. filipendula mass (Fig. 4).

\section{DISCUSSION}

Despite acknowledging that the processes affecting populations are likely to vary with scale, it is rare for experimentalists to determine whether predictions generated by small-scale experiments are manifested at larger scales. The results of our small-scale experiments demonstrated that recruitment of slippery dicks is strongly influenced by the density and biomass of Sargassum filipendula (also see Levin \& Hay 1996). This small-scale recruitment response qualitatively predicted larger-scale patterns of use by slippery dicks in both $100 \mathrm{~m}^{2}$ experimental habitats scattered over a few kilometers and on larger reefs separated by up to $30 \mathrm{~km}$. In spatially heterogeneous systems, such as reefs, the results of small-scale experiments should predict patterns at larger scales as long as the experi- 
ment adequately includes the important processes operating across the scales of investigation (Sale 1998). The consistency of our results across spatial scales (and across experiments and measurements using different methodologies - additions, removals, and correlations) suggests that processes mediated by habitat availability are important to slippery dicks on temperate reefs in the South Atlantic Bight.

Selection for specific habitats at settlement may overwhelm variation in larval supply, thus producing variability in recruitment that is associated with variability in the preferred habitat (Doherty \& Fowler 1994). Although slippery dicks occur in a wide variety of temperate and tropical habitats (coral reefs, backreef rubble, jetties, seagrass beds, etc.) and thus appear to be habitat generalists over broad geographic scales, on the reefs we studied, slippery dicks showed a strong preference for the Sargassum filipendula habitat. Selection for this habitat may have produced the strong scale-insensitive association we observed. In order for habitat selection at settlement to predict patterns of abundance at later life history stages, older fish must use the same $S$. filipendula habitat, or if there are ontogenetic shifts in habitat, the demographic importance of habitat to older fish must be lower than the importance of habitat selection at settlement. Our previous work (Levin \& Hay 1996) suggests that $S$. filipendula is preferentially used by adult slippery dicks. Thus, at least in our study sites, it seems likely that the association with a specific habitat throughout the life history of the fish results in the ability of scale-up from small-scale patterns of recruitment.

Clearly, many factors are important in determining when small-scale experiments will predict large-scale patterns of abundance. Since seaweeds may provide newly recruited fishes with both shelter from predation and food resources, the degree to which small-scale habitat preferences are observed at larger scales may be a complex function of levels of recruitment, the risk of predation and adequate food supply (Hixon \& Menge 1991). For example, if seaweed beds function primarily as refuges from predation, then when predation risk is low, fishes may be less dependent on seaweed habitat. Since fishes may then use alternative habitats, the availability of preferred habitats may not determine large-scale patterns. Similarly, if recruitment is low and food is plentiful, seaweed abundance may not be the leading determinant of large-scale population size. Rather, among-reef variability in recruitment would determine population size. Thus, understanding the mechanisms selecting for specific microhabitat use, and how this varies among species, will be critical in formulating generalizations about the processes that determine the population size of reef fishes and how these processes will vary with scale.
While habitat is clearly significant to slippery dicks, the magnitude of this effect appears to decrease with increasing spatial scale. In our small-scale experiment, a doubling of Sargassum filipendula yielded a nearly 7 -fold increase in the density of slippery dicks. In contrast, our results indicate that a doubling of $S$. filipendula at a scale of kilometers yields about 1.5 times more slippery dicks. Thus, it seems that the strong pattern of habitat association generated at a scale of meters is diluted by variability in larval supply or other processes occurring at large scales.

Many studies of reef fishes attempting to extrapolate small-scale patterns of habitat use to larger scales have not succeeded. Tolimieri (1995), for example, demonstrated strong patterns of microhabitat use by recruits of the damselfish Stegastes planifrons; however, he found no relationship between the availability of the chosen microhabitat and recruitment to 9 reefs throughout the Virgin Islands. Similarly, Caselle \& Warner (1996) demonstrated a correlation between microhabitat attributes and recruitment of Thalassoma bifasciatum that was not evident among sites around St Croix, US Virgin Islands. On temperate reefs, Levin (1991, 1993) showed that the wrasse Tautogolabrus adspersus selected microhabitats with high coverage of filamentous algae at settlement, but among-reef variability in filamentous algae did not predict large-scale patterns of recruitment (Levin et al. 1997). The inability to scale-up may occur because of low variability of the preferred substratum (Tolimieri 1995) or because the habitat signal may be scale-dependent (Syms 1995, Syms \& Jones 1999).

While many studies have failed to successfully scaleup small-scale results, this result is not universal. For example, Tolimieri (1998a) showed that large-scale patterns of adult abundance in a parrotfish and 4 damselfishes were related to patterns of microhabitat availability. For the damselfish Stegastes dorsopunicans, $84 \%$ of the among-reef variance was explained by availability of preferred microhabitats. Tolimeri's work, however, was designed to test only whether the direction of the response to habitat scaled-up, not the magnitude of the response.

Nearly all pressing problems in ecology and conservation biology require metrics enumerated at one scale to be scaled-up from measured to expected values (Schneider 1994). Our results highlight the observation that simply knowing the direction of the response is insufficient; one also needs information about the strength of the response and how the response changes across scales. For example, the goal of many habitat restoration projects is to achieve a particular density of a target species. Knowing that a species is associated with a habitat suggests that restoration of that habitat is desirable. However, small-scale studies 
may not inform decisions about the quantity of the habitat that will need to be restored in order to achieve a particular density of a target species. Additionally, it is important to recognize that there are several aspects of scaling, and we consider only one of them - the prediction of large-scale patterns as a function of smallscale processes. Other issues of scale such as the role of study extent and grain in detecting pattern, or changes in variability of populations and communities with scale are clearly important (e.g. Addicott et al. 1987, Wiens 1989, Sale 1998), and our understanding of reef fishes will gain precision as researchers investigate these and other aspects of scaling.

Progress in formulating generalizations concerning the ecology of reef fishes may be hampered by a failure to recognize the roles of both pre- and post-settlement processes or how these processes vary with scale (Hixon 1998); however, neglecting the ecological and behavioral attributes of individual species may also be a key obstacle in producing useful generalizations about processes affecting reef fish dynamics (cf. Syms \& Jones 1999). By investigating differences among species, such as the degree to which habitat selection at small scales translates to patterns of distribution and abundance at larger scales, we may uncover generalizations that have heretofore been obscured by attempts to generalize from data gathered on organisms that respond to their habitat in fundamentally different ways.

Acknowledgements. We appreciate the field assistance provided by Dan Aspenliter, Robin Bolser, Greg Cronin, Mike Deal, Ken Johns, Greg McFall, Margaret Miller, Glenn Safrit, Jay Stachowicz, Glen Taylor and Kevin Violeta. Comments by P. Kareiva, C. Peterson, P. Petraitis, and T. Minchinton improved the manuscript. We are grateful for support provided by NURC grants 9209, 9304, 9411, NSF grants OCE 92-02487, 95-29784, DEB-9610353, and MARFIN grant NA57FF0057.

\section{LITERATURE CITED}

Addicott JF, Aho JM, Antolin MF, Padilla DK, Richardson JS, Soluk DA (1987) Ecological neighborhoods: scaling environmental patterns. Oikos 49:340-346

Bohlke JE, Chaplin CG (1993) Fishes of the Bahamas and adjacent tropical waters. 2nd edn. University of Texas Press, Austin

Booth DJ, Wellington G (1998) Settlement preferences in coral-reef fishes: effects on patterns of adult and juvenile distributions, individual fitness and population structure. Aust J Ecol 23:274-279

Caley MJ, Carr MH, Hixon MA, Hughes TP, Jones GP, Menge BA (1996) Recruitment and the local dynamics of open marine populations. Annu Rev Ecol Syst 27:477-500

Carr MH (1991) Habitat selection and recruitment of an assemblage of temperate zone reef fishes. J Exp Mar Biol Ecol 146:113-137

Caselle JE, Warner RR (1996) Variability in recruitment of coral reef fishes: the importance of habitat at two spatial scales. Ecology 77:2488-2504

Chapman ARO, Johnson CR (1990) Disturbance and organization of macroalgal assemblages in the Northwest Atlantic. Hydrobiologia 192:77-121

Choat JH, Ayling AH (1987) The relationship between habitat structure and fish faunas on New Zealand reefs. J Exp Mar Biol Ecol 110:257-284

Doherty PJ, Fowler A (1994) Demographic consequences of variable recruitment to coral reef fish populations: a congeneric comparison of two damselfishes. Bull Mar Sci 54: 297-313

Doherty PJ, Williams DMcB (1988) The replenishment of coral reef fish populations. Oceanogr Mar Biol Annu Rev 26: 487-551

Ebeling AW, Laur DR (1985) The influence of plant cover on surfperch abundance at an offshore temperate reef. Environ Biol Fish 12:169-179

Grimes CB, Manooch CS, Huntsman GR (1982) Reef and rock outcropping fishes of the outer continental shelf of North Carolina and South Carolina, and ecological notes on the red porgy and vermilion snapper. Bull Mar Sci 31:277-289

Hixon MA (1998) Population dynamics of coral-reef fishes: controversial concepts and hypotheses. Aust J Ecol 23: 192-201

Hixon MA, Menge BA (1991) Species diversity: prey refuges modify the interactive effects of predation and competition. Theor Popul Biol 39:178-200

Holbrook SJ, Schmitt RJ (1988) The combined effects of predation risk and food reward on patch selection. Ecology 69:125-134

Holbrook SJ, Schmitt RJ, Ambrose RF (1990) Biogenic habitat structure and characteristics of temperate reef fish assemblages. Aust J Ecol 15:489-503

Jones GP (1984) Population ecology of the temperate reef fish Pseudolabrus celidotus Bloch \& Schneider (Pisces: Labridae). I. Factors influencing recruitment. J Exp Mar Biol Ecol 75:257-276

Levin PS (1991) Effects of microhabitat on recruitment variation in a temperate reef fish. Mar Ecol Prog Ser 75:183-189

Levin PS (1993) Habitat structure, conspecific presence and spatial variation in the recruitment of a temperate reef fish. Oecologia 94:176-185

Levin PS (1994) Small-scale recruitment variation in a temperate fish: the roles of macrophytes and food supply. Environ Biol Fish 40:271-281

Levin PS, Hay ME (1996) Responses of temperate reef fishes to alterations in algal structure and species composition. Mar Ecol Prog Ser 134:37-47

Levin PS, Chiasson W, Green JM (1997) Geographic differences in recruitment and population structure of a temperate reef fish. Mar Ecol Prog Ser 161:23-35

Levin SA (1992) The problem of pattern and scale in ecology. Ecology 73:1943-1967

Randall JE (1968) Caribbean reef fishes. TFH Publications Inc, Neptune, NJ

Renaud PE, Ambrose WG, Riggs SR, Syster DA (1996) Multilevel effects of severe storms on an offshore temperate reef system: benthic sediments, macroalgae and implications for fisheries. PSZN I: Mar Ecol 17:383-398

Renaud PE, Riggs SR, Ambrose WG, Schmid K, Snyder SW (1997) Biological-geological interactions: storm effects on macroalgal communities mediated by sediment characteristics and distribution. Cont Shelf Res 17:37-56

Riggs SR, Snyder SW, Hine AC, Ellington SW, Mallette PM (1985) Geologic framework of phophorite resources in Onslow Bay, North Carolina continental shelf. Econ Geol 80:716-738 
Sale PF (1991) Introduction. In: Sale PF (ed) The ecology of fish on coral reefs. Academic Press, San Diego, p 3-16

Sale PF (1998) Appropriate spatial scales for studies of reeffish ecology. Aust J Ecol 23:202-208

Sale PF, Douglas WA (1981) Precision and accuracy of visual census techique for fish assemblages on coral patch reefs. Environ Biol Fish 6:333-339

Schmitt RJ, Holbrook SJ (1985) Patch selection by juvenile surfperch (Embiotocidae) under variable risk: interactive influence of food quality and structural complexity. J Exp Mar Biol Ecol 85:269-285

Schneider DC (1994) Quantitative ecology. Academic Press, San Diego

Sedberry GR, van Dolah RF (1984) Demersal fish assemblages associated with hard bottom habitat in the South Atlantic Bight of the USA. Environ Biol Fish 11:241-258

Steinberg PD, Estes JA, Winter FC (1995) Evolutionary consequences of food chain length in kelp forest communities. Proc Natl Acad Sci USA 92:8145-8148

Syms C (1995) Multi-scale analysis of habitat association in a guild of blennioid fishes. Mar Ecol Prog Ser 125:31-43

Syms C, Jones GP (1999) Scale of disturbance and the structure of a temperate fish guild. Ecology 80:921-940

Thresher RE (1979) Social behavior and ecology of two sympatric wrasses (Labridae: Halichoeres spp.) off the coast of Florida. Mar Biol 53:161-172

Tolimieri N (1995) Effects of microhabitat characteristics on the settlement and recruitment of a coral reef fish at two spatial scales. Oecologia 102:52-63

Editorial responsibility: Charles Peterson (Contributing Editor), Morehead City, North Carolina, USA
Tolimieri N (1998a) Contrasting effects of microhabitat use on large-scale adult abundance in two families of Caribbean reef fishes. Mar Ecol Prog Ser 167:227-239

Tolimieri N (1998b) Effects of substrata, resident conspecifics and damselfish on the settlement and recruitment of the stoplight parrotfish, Sparisoma viride. Environ Biol Fish 53:393-404

Tupper M, Boutilier RG (1997) Effects of habitat on settlement, growth, and survival of a temperate reef fish. Mar Ecol Prog Ser 151:225-236

Victor BC (1982) Daily growth increments and recruitment in two coral-reef wrasses, Thalassoma bifasciatum and Halichoeres bivattus. Mar Biol 71:203-208

Victor BC (1983) Settlement and larval metamorphosis produce distinct marks on the otoliths of the slippery dick Halichoeres bivattus. In: Reaka ML (ed) The ecology of deep and shallow coral reefs (NOAA Symp Ser Undersea Res). National Oceanic and Atmospheric Administration, Rockville, MD, p 47-51

Victor BC (1986) Duration of the planktonic larval stage of one hundred species of Pacific and Atlantic wrasses (family Labridae). Mar Biol 90:317-326

Wiens JA (1989) Spatial scaling in ecology. Funct Ecol 3: 385-397

Wilkinson L, Blank G, Gruber C (1996) Desktop data analysis with SYSTAT. Prentice Hall, Upper Saddle River, NJ

Winer BJ, Brown DR, Michels KM (1991) Statistical principles in experimental design, 3rd edn. McGraw-Hill, New York

Submitted: April 11, 2001; Accepted: November 2, 2001

Proofs received from author(s): April 2, 2002 